\title{
TANTANGAN PENERAPAN INOVASI DI KOTA SABANG
}

\section{THE CHALLENGE IMPLEMENTING INNOVATIONS IN SABANG CITY}

\author{
Henri Prianto Sinurat ${ }^{1}$; Rati Sumanti ${ }^{1}$ \\ ${ }^{1}$ Puslatbang Kajian Hukum Administrasi Negara \\ Email: henrisinurat@yahoo.co.uk,ratisumanti@gmail.com
}

\begin{abstract}
Abstrak
Faktor penting untuk mendorong peningkatan daya saing dan kemakmuran daerah adalah inovasi. Di lingkup pemerintahan daerah, inovasi terdiri dari inovasi tata kelola pemerintahan daerah dan inovasi pelayanan publik. Penerapan inovasi tersebut meghadapi tantangan baik yang datang dari internal maupun eksternal organisasi. Pada 2017, Pemerintah Kota Sabang telah memulai langkah percepatan inovasi di daerahnya dengan membentuk program Laboratorium Inovasi. Program tersebut bertujuan mengadvokasi Pemerintah Daerah untuk melahirkan ide/gagasan inovasi sampai mengimplementasikan inovasi. Aktor penting yang berperan adalah Satuan Kerja Perangkat Kota (SKPK) yang ada di Pemerintah Kota sabang, SKPK merupakan garda terdepan yang menjalankan birokrasi pemerintahan baik yang berhubungan dengan tata kelola pemerintahan maupun pelayanan publik. Program Laboratorium Inovasi Pemerintah Kota Sabang, terdiagnose ada 89 ide/gagasan inovasi dari 21 SKPK dan 6 Puskesmas. 89 ide/gagasan inovasi tersebut hanya 47 ide/gagasan inovasi yang tertuang dalam kontrak kinerja antara kepala SKPK dengan Walikota Sabang. Penelitian ini telah memetakan tantangan yang dihadapi oleh Pemerintah Kota Sabang dalam penerapan inovasi. Menggunakan metode kualitatif dengan teknik pengumpulan data melalui wawancara, telaah dokumen dan observasi, diperoleh tantangan penerapan inovasi di Sabang. Tujuannya agar ditemukan solusi untuk mengatasinya sehingga inovasi yang sudah direncanakan dapat berjalan secara maksimal. Adapun tantangan penerapan inovasi di Sabang dipengaruhi oleh faktor internal seperti sumber daya manusia, budaya organisasi, kepemimpinan dan anggaran, sedangkan faktor eksternal dipengaruhi oleh partisipasi masyarakat.
\end{abstract}

Kata Kunci: inovasi; pelayanan publik; pemerintah daerah

\begin{abstract}
An important factor to encourage increased regional competitiveness and prosperity is innovation. In the scope of regional government, innovation consists of innovation in local governance and innovation in public services. The application of these innovations faces challenges both from internal and external to the organization. In 2017, the Sabang City Government has begun to accelerate innovation in its area by forming an Innovation Laboratory program. The program aims to advocate for local governments to produce ideas / innovations to implement innovation. An important actor who plays a role is the City Work Unit (SKPK) in the Sabang City Government, SKPK is the frontline that runs the
\end{abstract}


government bureaucracy both related to governance and public services. The Sabang City Government Innovation Laboratory Program, diagnosed there are 89 innovative ideas from 21 SKPK and 6 Puskesmas. 89 innovation ideas / ideas are only 47 innovative ideas / ideas contained in the performance contract between the SKPK head and Sabang Mayor. This research has mapped the challenges faced by the Sabang City Government in applying innovation. Using qualitative methods with data collection techniques through interviews, document review and observation, obtained challenges in the application of innovation in Sabang. The goal is to find a solution to overcome them so that innovations that have been planned can run optimally. The challenges of applying innovation in Sabang are influenced by internal factors such as human resources, organizational culture, leadership and budget, while external factors are influenced by community participation.

Keywords: innovation; public service; local government

\section{Pendahuluan}

Pemerintah daerah mempunyai peranan penting dalam memberikan layanan kepada publik (Walker and Andrews 2015). Pemerintah daerah menjadi perpanjangan tangan pemerintah pusat dalam memberikan pelayanan publik. Terpenuhinya kebutuhan pelayanan publik akan berbanding lurus terhadap kepercayaan masyarakat kepada pemerintah. Ketidakpercayaan publik sering muncul akibat dari buruknya fungsi layanan publik (Van de Walle and Bouckaert 2003). Untuk meningkatkan kepercayaan masyarakat, maka dibutuhkan penguatan dan perbaikan kualitas pelayanan publik. Pemerintah Indonesia melalui Undang-Undang Nomor 25 Tahun 2009 tentang Pelayanan Publik, telah menetapkan standar pelayanan publik untuk masyarakat.

Inovasi menjadi salah satu strategi pemerintah daerah dalam memperbaiki kualitas pelayanan publik. Hal ini didukung dengan lahirnya Undang-Undang Nomor 23 Tahun 2014 tentang Pemerintahan Daerah. Penyelenggaraan inovasi di daerah juga didukung dengan Peraturan Pemerintah Nomor 38 Tahun 2017 tentang Inovasi Daerah. Berdasarkan PP Nomor 38 Tahun 2017, inovasi daerah adalah semua bentuk pembaharuan dalam penyelenggaraan Pemerintahan Daerah. Inovasi daerah terdiri atas inovasi tata kelola Pemerintahan Daerah dan inovasi Pelayanan Publik; dan/atau Inovasi Daerah lainnya sesuai dengan Urusan Pemerintahan yang menjadi kewenangan Daerah.

Inovasi di daerah mengalami tantangan dalam penerapannya. Memang setiap daerah berpeluang memanfaatkan seluruh sumber daya yang dimiliki untuk berkreativitas melahirkan ide dan gagasan menciptakan inovasi. Namun di sisi lain, penerapan inovasi daerah juga berpotensi menyebabkan terjadinya penyalahgunaan wewenang. Untuk menjamin terlaksananya inovasi daerah dalam Peraturan Pemerintah ini diatur batasan tegas mengenai hal tersebut, yaitu dengan pengaturan secara rinci dan jelas mengenai prinsip, kriteria, dan mekanisme Inovasi Daerah sebagai suatu kebijakan Daerah. Hal tersebut sangat penting untuk menghindari adanya penyalahgunaan wewenang oleh Pejabat Pemerintah Daerah. 
Pemerintah Kota Sabang turut serta dalam penyelenggaraan inovasi pelayanan publik. Sebagai daerah terluar dan berada dalam kawasan yang terpisah dari Pulau Sumatera, menjadikan Pemerintah Kota Sabang mempunyai tantangan tersendiri dalam penyelenggaraan inovasi pelayanan publik. Pelayanan publik merupakan sektor yang penting untuk mendapatkan sentuhan inovasi, meskipun sering tidak dipahami dan diabaikan (De Vries, Bekkers, \& Tummers, 2016; Osborne \& Brown, 2013; Windrum \& Koch, 2008).

Pemerintah Kota Sabang berupaya melakukan percepatan inovasi melalui pembentukan laboratorium inovasi daerah bekerjasama dengan Lembaga Administrasi Negara. Dimulai sejak 2017, Pemerintah Kota Sabang melalui Badan Perencanaan dan Pembangunan Daerah Kota Sabang (Bappeda Sabang) telah mengidentifikasi ide/gagasan inovasi di setiap Satuan Kerja Perangkat Daerah (SKPD). Namun pada tingkat penerapannya, inovasi di Pemerintah Kota Sabang masih mengalami tantangan baik yang datang dari internal maupun eksternal organisasi. Berdasarkan hal tersebut, penulis membahas tantangan inovasi di daerah. Tujuannya adalah untuk mengetahui strategi menghadapi tantangan.

Inovasi sebagai sesuatu yang baru yaitu dengan memperkenalkan dan melakukan praktek atau proses baru (barang atau layanan) atau bisa juga dengan mangadopsi pola baru yang berasal dari organisasi lain (Thenint 2010). Penerapan inovasi di sektor publik dapat mengadopsi dan atau memperbaharui inovasi yang telah ada pada sektor publik lainnya. United Nations (2006:2) menegaskan bahwa inovasi bertujuan untuk merevitalisasi administrasi publik, membuatnya lebih proaktif, efisien, akuntabel, dan lebih berorientasi pada pelayanan. Sehingga penerapan inovasi di sektor publik bertujuan untuk meningkatkan kualitas pelayanan publik.

Penyelenggaraan inovasi di sektor publik dipengaruhi oleh berbagai faktor, baik dari internal maupun dari eksternal. Budaya inovasi dapat didefinisikan sebagai "budaya tempat suatu kelompok dari nilai-nilai yang dibagikan orang, kebiasaan dan asumsi kondusif untuk ide-ide baru dan perubahan organisasi" (Bason 2010). Literatur menunjukkan bahwa budaya organisasi atau tempat kerja untuk inovasi adalah faktor signifikan dalam mendukung atau menghambat inovasi sektor publik (Albury 2005; Lægreid, Roness, and Verhoest 2011). Banyak faktor yang dapat mempengaruhi budaya inovasi, termasuk metode tata kelola dan karakteristik pribadi manajer, seperti apakah seorang manajer memiliki "pola pikir kewirausahaan" (Damanpour and Schneider 2006).

Untuk menjamin kesuksesan inovasi diperlukan dukungan sumber daya manusia yang kompeten (Anatan.2007; Chaudury.2010), budaya perusahaan yang mendukung inovasi (Dagi.2010; Chaudury.2010; Glor.2001), strategi perusahaan (Chaudury.2010; Manurung. 2010,) dan struktur perusahaan (Kohli \& Jaworsky, 1990, Ettlie, 1984, Chaudury, 2010, Manurung, 2010). Faktor-faktor internal tersebut sangat mempengaruhi keberhasilan inovasi dalam sebuah perusahaan. Faktor-faktor yang mempengaruhi inovasi di sektor swasta tidak jauh berbeda dengan 
sektor publik. Berdasarkan pendapat dari pakar tersebut di atas, penerapan inovasi dipengaruhi oleh sumber daya manusia, budaya organisasi, kepemimpinan, anggaran dan partisipasi masyarakat.

\section{Metode Penelitian}

Penelitian ini menggunakan metode kualitatif bersifat deskriftif. Penelitian kualitatif adalah penelitian yang bermaksud untuk memahami fenomena tentang apa yang dialami oleh subjek penelitian secara holistik dan dengan cara deskripsi dalam bentuk kata-kata dan bahasa, pada suatu konteks khusus yang alamiah dengan memanfaatkan berbagai metode alamiah (Moleong, 2012). Penelitian kualitatif dalam rangka melihat tantangan dalam penerapan inovasi-inovasi di Pemerintah Kota Sabang. Adapun teknik pengumpulan data yang digunakan dalam penelitian ini menggunakan metode wawancara terhadap pelaksana inovasi, telaah dokumen dan observasi.

\section{Hasil dan Pembahasan}

Tuntutan atas peningkatan kualitas pelayanan publik memaksa pemerintah daerah untuk bekerja keras dalam melayani masyarakat. Inovasi merupakan solusi dalam perbaikan kualitas pelayanan publik. Pemerintah Kota Sabang mencanangkan gerakan berinovasi di sektor pelayanan publik pada tahun 2017. Meskipun pada tahun-tahun sebelumnya terdapat beberapa inovasi, akan tetapi belum terselenggara secara massive. Pada tahun 2017 terdapat 89 gagasan inovasi yang digagas oleh seluruh Satuan Kerja Perangkat Daerah (SKPD) Kota Sabang. Pada tahun 2018 terdapat 47 inovasi yang ditetapkan oleh Pemerintah Kota Sabang. Hal ini ditandai dengan adanya penandatangan Kontrak Kinerja Inovasi antara Walikota Sabang dengan Kepala SKPD penyelenggara inovasi. Penerapan inovasi di Kota Sabang menghadapi berbagai tantangan dalam penyelenggaraannya. Penerapan inovasi di Kota Sabang dipengaruhi oleh faktor internal seperti sumber daya manusia, budaya organisasi, kepemimpinan dan anggaran, sedangkan faktor eksternal dipengaruhi oleh partisipasi masyarakat.

\section{Sumber Daya Manusia}

Penerapan inovasi di SKPD turut dipengaruhi oleh komitmen sumber daya manusia (SDM) SKPD. Peranan SDM sangat dibutuhkan dalam proses perencanaan, pelaksanaan hingga evaluasi inovasi. Komitmen SDM akan mendukung kelancaran sebuah inovasi, sehingga inovasi yang diterapkan tidak akan menimbulkan permasalahan baru. Kesadaran SDM dalam melaksanakan inovasi akan berimplikasi terhadap peningkatan kinerja organisasi. Oleh karenanya, pelaksanaan inovasi tidak akan mengganggu penyelenggaraan tupoksi SKPD.

Kepala Puskesmas Iboih dalam catatan tertulisnya menyampaikan bahwa peranan dari SDM Puskesmas Iboih sangat mendukung terlaksananya inovasi Poli Igoe Rakan Aneuk Miet (POLIRAM). Poli Igoe Rakan Aneuk Miet dalam Bahasa Indonesia dapat diartikan sebagai Poli Gigi Sahabat Anak-Anak. POLIRAM 
merupakan inovasi yang bertujuan untuk meningkatkan kepercayaan dan minat anak-anak dalam menjaga kesehatan gigi. Sebelum inovasi POLIRAM digagas, anakanak di Iboih merasa takut dan cemas untuk datang ke Poli Gigi. Puskesmas Iboih menerima kunjungan siswa-siswi Taman Kanak-Kanak setiap Hari Sabtu setiap pekannya. Petugas pelaksana inovasi POLIRAM merubah maindset anak-anak agar tidak cemas. Petugas menyambut kedatangan anak-anak dengan menerapkan pendekatan yang lebih humanis, ramah anak, dan edukatif.

Kemampuan petugas yang humanis, ramah anak dan edukatif tidak dimiliki oleh semua Petugas Puskesmas Iboih. Kepala Puskesmas hanya mampu mendorong agar petugas poli gigi untuk mempunyai kemampuan-kemampuan tersebut. Kemauan dari petugas poli gigi itu sendiri yang sangat menentukan terselenggaranya inovasi POLIRAM dengan baik. Kepala Puskesmas Iboih menyatakan bahwa POLIRAM merupakan inovasi kolektif, sehingga tidak dapat berjalan dengan sendirinya tanpa dukungan dari Petugas Poli Gigi. Kemampuan SDM dalam beradaptasi atas perubahan-perubahan yang ada di Puskesmas Iboih juga mendorong pelaksanaan inovasi.

\section{Budaya Organisasi}

Budaya organisasi merupakan kegiatan yang menjadi kebiasaan dalam sebuah struktur organisasi. Budaya organisasi dibutuhkan dalam instansi pemerintahan dalam rangka penerapan nilai-nilai positif dalam organisasi. Sehingga budaya organisasi akan mempengaruhi prilaku setiap insan dalam sebuah organisasi. Budaya organisasi yang menghindari adanya resiko akan menghambat eksperimen berinovasi. Sejatinya budaya organisasi dapat mendorong instansi pemerintahan dalam pencapaian tujuan organisasi.

Kesibukan pada rutinitas sehari-hari menjadikan aparatur mengabaikan tugastugas tambahan yang baru. Aparatur menafsirkan bahwa penerapan inovasi merupakan tugas tambahan yang menjadi beban baru dalam pelaksanaan tugas. Aparatur belum terbiasa dalam hal menciptakan gagasan-gagasan baru dalam peningkatan pelayanan publik. Masih ada aparatur yang belum terbiasa dengan adanya perubahan. Tetapi tidak dapat dipungkiri bahwa budaya top-down juga turut mempengaruhi lahirnya ide-ide inovasi. Gagasan inovasi cenderung berasal dari pimpinan, sehingga menghambat partisipasi dari bawahan. Hanya inovasi-inovasi yang berasal dari pimpinan organisasi yang akan diselenggarakan. Aparatur pelaksana menghindari munculnya resiko terutama yang berkaitan dengan pembiayaan sebuah inovasi. Kegagalan pelaksanaan inovasi akan dikonotasikan sebagai kegagalan kinerja pemerintah daerah. Kondisi seperti ini tentunya menjadi sebuah tantangan tersendiri bagi instansi pemerintahan dalam penerapan inovasi.

Melekatnya nilai-nilai kepedulian dalam budaya organisasi pada instansi pemerintahan turut mendorong penerapan inovasi. Kepala Puskesmas Pria Laot menyatakan bahwa pegawai di Puskesmas Pria Laot sangat berperan dalam penyelenggaraan inovasi. Dukungan tersebut dipengaruhi oleh kebiasaan saling peduli dan bekerjasama yang telah ada di Puskesmas Pria Laot. Sehingga Kepala 
Puskesmas Pria Laot tidak menghadapi hambatan yang berarti dalam penyampaian gagasan kegiatan inovasi. Proses membangun budaya berinovasi di Puskesmas Pria Laot karena sebelumnya sudah ada budaya kinerja dalam berorganisasi.

Iklim kerja yang baik akan tercipta seiring dengan penerapan budaya kerja yang baik. Seperti budaya kerja berbagi pengetahuan (knowledge sharing) yang dilaksanakan secara rutin. Konsistensi kegiatan berbagi pengetahuan melahirkan budaya saling berbagi dan peduli antar pegawai. Pegawai akan bekerjasama dalam menyelesaikan kegiatan-kegiatan di Puskesmas Pria Laot. Hadirnya inovasi akan membuka ruang untuk pegawai bebas berekspresi melahirkan gagasan-gagasan baru. Gagasan inovasi yang sesuai dengan tugas pokok dan fungsi SKPD akan mendorong pencapaian visi dan misi daerah. Kebebasan berpendapat tidak hanya dalam menggagas inovasi, tetapi juga dalam konteks memberikan solusi jika inovasi yang diselenggarakan mendapatkan hambatan.

\section{Kepemimpinan}

Komitmen pimpinan SKPD merupakan faktor utama yang menghambat maupun mendukung penerapan inovasi. Ketidakberlanjutan gagasan inovasi dipengaruhi oleh kebijakan dan komitmen pimpinan sebagai faktor internal. Perubahan kebijakan yang kerap terjadi membuat sebuah inovasi berjalan di tempat. Bahkan tidak jarang kebijakan membuat inovasi terhenti. Pertaruhan keberlanjutan inovasi juga sangat ditentukan oleh komitmen pimpinan. Jika tidak ada dukungan dari pimpinan maka wajar jika sebuah kegiatan inovasi akan terhenti. Perubahan struktur kelembagaan di daerah menjadi faktor utama yang kerap menyebabkan gagasan inovasi tidak berlanjut. Kegiatan yang telah diusulkan tidak dapat lagi dilanjutkan karena tidak sejalan dengan visi dan misi pimpinan SKPD yang baru. Bahkan adanya peleburan dan perubahan struktur kelembagaan di SKPD menjadi tantangan tersendiri karena menghilangkan rumah kegiatan dalam pelaksanaan inovasi. Tanpa adanya dukungan kebijakan maka aparatur dalam instansi tersebut akan ragu untuk melaksanakan inovasi. Bahkan instansi / lembaga tidak mau melanjutkan kegiatan inovasi karena tidak ada keharusan yang diperkuat oleh kebijakan pimpinan. Instasi / lembaga menjadi acuh tak acuh terutama tanpa ada dukungan dari komitmen pimpinan.

Komitmen Kepala SKPD tidak hanya dalam melahirkan kebijakan, tetapi juga terlihat dalam penyelenggaraan inovasi. Kepala SKPD hadir dan memberikan arahan dalam setiap pertemuan inovasi. Fungsi kepemimpinan akan mempengaruhi penyelenggaraan inovasi terutama dalam memberikan saran dan masukan. Kepala SKPD akan berperan dalam mempengaruhi bawahan dan stakeholder dalam penerapan inovasi. Kemampuan Kepala SKPD juga dibutuhkan dalam memahami karakteristik individu SDM untuk meningkatkan produktivitas kerja. Sehingga akan mengurangi dampak dan kegagalan penyelenggaraan inovasi.

\section{Anggaran}

Sejatinya inovasi tidak selalu berkenaan dengan ketersediaan anggaran. Karena inovasi-inovasi dapat berupa perubahan cara kerja dan prilaku saja dalam pelaksanaan 
pelayanan publik. Sehingga tidak membutuhkan banyak biaya. Gagasan inovasi SAPU LIDI (Saya Punya Layanan Lima Belas Menit Jadi) yang diusung oleh Dinas Kependudukan dan Pencatatan Sipil Kota Sabang, merupakan inovasi yang merubah prilaku kerja dalam pelayanan publik. Inovasi Sapu Lidi hanya membutuhkan komitmen SDM Disdukcapil. Kota Sabang tanpa membutuhkan anggaran yang besar.

Meskipun demikian, terdapat inovasi-inovasi yang membutuhkan dukungan anggaran. Lahirnya kebijakan dalam pelaksanaan sebuah inovasi tentunya akan dipengaruhi juga oleh ketersediaan anggaran di SKPD. Aparatur SKPD tidak mempunyai kewenangan untuk merubah struktur anggaran kegiatan SKPD. Usulan perubahan struktur anggaran kerap mendapat hambatan sehingga tidak sesuai dengan harapan. Aparatur-aparatur di Kota Sabang cenderung menyatakan bahwa penyediaan anggaran untuk pelaksanaan inovasi tidak dapat disediakan secara instan, harus melalui proses pengusulan Anggaran Pendapatan dan Belanja Daerah. Kondisi lainnya adalah adanya peleburan struktur organisasi menyebabkan anggaran yang tersedia tidak mampu mendorong penyelenggaraan maupun keberlanjutan inovasi di daerah.

Kebutuhan anggaran tidak hanya dalam penciptaan inovasi. Penguatan inovasi melalui pengembangan kapasitas aparatur dan peningkatan sarana prasarana juga harus mendapatkan perhatian khusus. Beberapa gagasan inovasi di Kota Sabang membutuhkan dukungan teknologi informasi dan komunikasi (TIK), hanya saja fasilitas ini belum semuanya tersedia. Peralatan TIK yang tersedia belum mampu mendukung pelaksanaan inovasi dengan baik. Inovasi yang dilaksanakan secara berkelanjutan merupakan investasi SKPD di masa mendatang. Sehingga dampak dari penerapan inovasi tidak serta merta dapat terlihat dalam waktu yang singkat.

Penyelenggaraan pembangunan daerah yang berkualitas adalah pembangunan yang partisipatif. Masyarakat dilibatkan dalam setiap perencanaan, penyelenggaraan hingga ke tahap evaluasi pembangunan. Inti dari partisipasi masyarakat adalah keterlibatan masyarakat dalam proses pengambilan keputusan yang menyangkut kepentingan masyarakat (Mikkelsen, 2011: 9-59). Inovasi-inovasi pelayanan publik yang diselenggarakan di Kota Sabang turut membutuhkan dukungan partisipasi masyarakat. Masyarakat tidak lagi menjadi objek kegiatan pemerintah, akan tetapi masyarakat turut menjadi subjek pembangunan.

Inovasi Minum Jamu Setiap Hari Jumat (MIJATJUM) adalah Gerakan minum jamu setiap hari Jumat yang dilaksanakan oleh masyarakat Kota Sabang. MIJATJUM merupakan gerakan meningkatkan kesehatan masyarakat. Inovasi ini lahir untuk mengurangi ketergantungan masyarakat dalam mengkonsumsi obat berbahan kimia. Dengan inovasi ini diharapkan kemandirian masyarakat dalam memanfaatkan Asman Toga (Asuhan Tanaman Obat Keluarga). Inovasi MIJATJUM digagas oleh Puskesmas Iboih yang memanfaatkan hasil Asman Toga di halaman puskesmas untuk dijadikan jamu. Minuman jamu diperkenalkan pada masyarakat yang berkunjung ke puskesmas. Kegiatan ini dilaksanakan setiap hari 
Jum'at dengan minum jamu bersama. Inovasi MIJATJUM akan berjalan apabila ada respon positif masyarakat. Masyarakat pengunjung puskesmas yang mau meminum jamu akan meningkatkan minat masyarakat lainnya untuk berpartisipasi dalam pelaksanaan inovasi MIJATJUM. Di awal pelaksanaannya, belum semua masyarakat yang berkunjung ke Puskesmas mau mendukung gerakan minum jamu. Setelah mendapatkan sosialisasi manfaat dan khasiat jamu tradisional, masyarakat berangsurangsur mau menerima dan berpartisipasi dalam kegiatan MIJATJUM. Tidak hanya berpartisipasi dalam kegiatan di Puskesmas, masyarakat juga turut mendukung kegiatan ini dengan membantu pengolahan tanaman obat menjadi minuman jamu. Secara tidak langsung, inovasi dapat meningkatkan kesejahteraan masyarakat.

Hadirnya kesadaran masyarakat dalam pelaksanaan inovasi, akan memberikan dukungan penyelenggaraan kegiatan pemerintah daerah. Dukungan tersebut akan menguatkan posisi pemerintah terutama dalam melahirkan kebijakan-kebijakan baru dalam peningkatan kualitas pelayanan publik. Partisipasi masyarakat akan mendorong adanya kolaborasi inovasi yang diselenggarakan. Selain menjadi partisipan, masyarakat akan menjadi pengawas penyelenggaraan inovasi. Sehingga penerapan inovasi akan sesuai dengan penjadwalan kegiatan yang telah direncanakan sebelumnya. Tanpa adanya dukungan masyarakat, inovasi pelayanan tidak akan berjalan dengan baik.

\section{Penutup}

Penerapan inovasi turut mewarnai penyelenggaraan pembangunan di daerah terutama sektor pelayanan publik. Inovasi terbukti mampu meningkatkan kinerja Satuan Kerja Perangkat Daerah. Berbagai kegiatan dan agenda dilaksanakan dalam rangka penguatan reformasi birokrasi. Peningkatan kualitas pelayanan publik diselenggarakan melalui metode percepatan layanan, pemangkasan birokrasi, serta meminimalisir penggunaan biaya. Meski demikian, tidak semua SKPD dapat dengan mudah menerapkan inovasi. Sumber daya manusia, budaya organisasi, kepemimpinan, anggaran dan partisipasi masyarakat menjadi tantangan terbesar dalam penerapan inovasi. Belum semua aparatur SKPD di Kota Sabang mampu menerima perubahan dengan cepat. Hal ini disebabkan oleh adanya rutinitas kerja yang lebih dulu ada sebelum hadirnya inovasi. Untuk menghadapi hal tersebut, dibutuhkan pengembangan kapasitas aparatur sehingga kompetensi aparatur akan meningkat. Budaya organisasi di SKPD Kota Sabang turut mendukung penyelenggaraan inovasi. Perbedaan persepsi antara aparatur dan Kepala SKPD akan menghambat pelaksanaan inovasi. Begitu juga dengan ketidakmampuan Kepala SKPD dalam mempengaruhi bawahannya untuk berinovasi. Ketersediaan anggaran akan mendukung kegiatan inovasi secara maksimal. Baik anggaran untuk pengembangan kapasitas aparatur maupun anggaran untuk penyediaan sarana dan prasarana yang mendukung penerapan inovasi. Belum semua SKPD mempunyai anggaran dalam rangka penyelenggaraan inovasi. Inovasi-inovasi yang dilaksanakan cenderung menggunakan anggaran yang minimalis. Partisipasi masyarakat menjadi 
unsur penting dalam penyelenggaraan kegiatan-kegiatan inovasi di Kota Sabang. Masyarakat sangat mendukung adanya penerapan inovasi-inovasi di sektor pelayanan publik setelah mendapatkan pemahaman akan dampak inovasi.

\section{Daftar Pustaka}

Albury, David. 2005. "Fostering Innovation in Public Services." Public Money and Management.

Anatan, Lina., 2007. Inovasi Produk dan Keunggulan Bersaing; Suatu Pandangan Berbasis Sumber Daya. MODUS Vol. 19(2):157- 165, Jurnal Ekonomi \&Bisnis. Yokyakarta

Anthopoulos, Leonidas, Christopher G. Reddick, Irene Giannakidou, and Nikolaos Mavridis. 2016. "Why E-Government Projects Fail? An Analysis of the Healthcare.Gov Website." Government Information Quarterly.

Askim, Jostein, Tom Christensen, Anne Lise Fimreite, and Per Lægreid. 2010. "How to Assess Administrative Reform? Investigating the Adoption and Preliminary Impacts of the Norwegian Welfare Administration Reform." Public Administration.

Bason, Christian. 2010. Leading Public Sector Innovation: Co-Creating for a Better Society Leading Public Sector Innovation: Co-Creating for a Better Society.

Chaudhury, S.R. 2010. Working Paper: Hidden attributes of huma resourcesfor successful innovation. http://papers.ssrn.com/sol3/papers.cfm?abstract_id=1589399

Chen, Yu-Cche, and James Perry. 2003. "Outsourcing for E-Government: Managing for Success.” Public Performance \& Management Review.

Coursey, David, and Donald F. Norris. 2008. "Models of E-Government: Are They Correct? An Empirical Assessment." Public Administration Review.

Dagi, William. 2010. Budaya Perusahaan Sebagai Sumber Motivasi Berinovasi, dalam Febransyah (editor); Prasetya Mulia on innovation Kekayaan Perspektif untuk Mendisain Hari Esok yang Lebih Baik. hal.218-251. Jakarta : Prasetya Mulia Publishing.

Damanpour, Fariborz, and Marguerite Schneider. 2006. "Phases of the Adoption of Innovation in Organizations: Effects of Environment, Organization and Top Managers." British Journal of Management. 
De Vries, Hanna, Victor Bekkers, and Lars Tummers. 2016. "Innovation in the Public Sector: A Systematic Review and Future Research Agenda." Public Administration.

Glor, Eleanor D. 2001. Key factors influencing innovation in government. The Innovation Journal; The Public Sector Innovation Journal Volume 6 (2).

Lægreid, Per, Paul G. Roness, and Koen Verhoest. 2011. "Explaining the Innovative Culture and Activities of State Agencies." Organization Studies.

Manurung, Laurensius. 2010. Strategi dan inovasi model bisnis meningkatkan kinerja usaha (Studi Empiris Industri Penerbangan). Jakarta : PT. Media Elex Komputindo - Kompas Gramedia

Mikkelsen B. 2011. Metode Penelitian Partisipatoris dan Upaya Pemberdayaan : Panduan Bagi Praktisi Lapangan. Jakarta : Yayasan Pustaka Obor Indonesia.

Moleong, L. (2011). Metodelogi Penelitian Kualitatif Edisi Revisi. Bandung: Remaja Rosdakarya.

Moon, M. Jae. 2002. "The Evolution of E-Government among Municipalities: Rhetoric or Reality?" Public Administration Review.

Moynihan, Donald P., and Stéphane Lavertu. 2012. "Cognitive Biases in Governing: Technology Preferences in Election Administration." Public Administration Review.

Osborne, Stephen P., and Louise Brown. 2013. Handbook of Innovation in Public Services Handbook of Innovation in Public Services.

Peraturan Pemerintah Nomor 38 Tahun 2017 tentang Inovasi Daerah.

Sinurat, Henri P. Peran Kepala Daerah Dalam Pelaksanaan Inovasi Daerah di Kabupaten Kepulauan Mentawai. Jurnal Kapita Selekta Administrasi Negara. Vol. 8 Nomor 2: 8-18. Lembaga Administrasi Negara: Jakarta

Thenint, H. 2010. "Global Review of Innovation Intelligence and Policy Studies Policy Studies Mini Study 10 Innovation in the public sector," no. February, 2010.

Undang-Undang Nomor 25 Tahun 2009 tentang Pelayanan Publik. 
Undang-Undang Nomor 23 Tahun 2014 tentang Pemerintahan Daerah.

United Nations, 2006, Innovations in Governance and Public Administration: Replicating what works, Department of Economic and Social Affairs.

Walker, Richard M., and Rhys Andrews. 2015. "Local Government Management and Performance: A Review of Evidence." Journal of Public Administration Research and Theory.

Van de Walle, Steven, and Geert Bouckaert. 2003. "Public Service Performance and Trust in Government: The Problem of Causality." International Journal of Public Administration.

Windrum, Paul, and Per Koch. 2008. Innovation in Public Sector Services: Entrepreneurship, Creativity and Management Innovation in Public Sector Services: Entrepreneurship, Creativity and Management.

Wood, Lawrence, Phyllis Bernt, and Carol Ting. 2009. "Implementing Public Utility Commission Web Sites: Targeting Audiences, Missing Opportunities." Public Administration Review. 